\title{
Emerging role of corporate treasury management in cyber space
}

\author{
J.H. van Rooyen \\ Department of Business Management \\ University of Stellenbosch \\ jvrooyen@sun.ac.za
}

\section{Contents}

1. Introduction

2. Objectives

3. Research methodology

4. Overview of the most important developments in information technology and business environment during recent years

5. Role and function of the corporate treasury department

6. New emerging role and position of the corporate treasury department

7. Importance of the future treasury from a management point of view

8. Summary, conclusion and recommendations

9. References

\section{Introduction}

The Internet has brought about many new implications for the way we do business and is becoming a feature of normal business (Forster 2000). The most important implication is the way in which the Internet links many different entities in a vast network, creating a pool of information that is accessible from any location in the world. The computer screen is a small window into this pool of information, allowing us to interact with other participants in cyberspace.

The most important aspect of the Internet from the point of view of this research is that it allows or facilitates the flow of business information, called e-business, between businesses and consumers, allowing business-to-business and business-to-consumer interaction.

One of the possibilities brought about by the Internet is that of trading on-line, also called ecommerce. This opens up a new world that allows trade with global markets from any location. The ease with which we change things (information) in this environment may cause us to be indifferent to the parties with which we do business - as long as we are able to verify their secure identities.

The modern treasury environment in a corporate treasury will be affected materially by the Internet. How treasury departments are being affected and will be affected in the future is 
important for South Africa. As a developing country, South Africa needs to take note of important changes in the global environment. If the country does not keep up with developments, the cost of catching up, which may be substantial, will place further unnecessary strain on the SA economy. E-business is seen as one of the most important enablers of business and it seems as if SA companies are already about 18 months to two years behind their counterparts in the USA (Gordon 2000:10). Generally, South African companies have not yet fully exploited the business advantages of new technologies (Duffield 2001:18).

South African corporate treasuries realize the benefits of the e-business environment but need to take note of the changes and requirements necessary to fully exploit these benefits and to enable them to better manage the overall treasury function and the increased exposure to financial risk which may come about owing to mismanagement, fraud, inefficient systems or the use of modern financial instruments. Devastating losses may come about owing to the incorrect use of, for instance, derivative financial instruments. These instruments may leverage a dramatic loss (Holton 1998) and may threaten the future existence of a company. It is today also much easier to place most or all of the capital of a company at risk with one phone call.

This just underlines how important it is to employ technology to improve the flow of business information for transactional, timely and accurate information for management purposes. The management of risk from the enterprise perspective therefore becomes vital.

\section{Objectives}

The main objectives of this research was to:

- summarize and clarify the main e-business developments in recent years that is affecting the way the modern corporate treasury department is managed;

- set out the major changes that will affect and are affecting the corporate treasury department; and

- describe the form of the future corporate treasury and the significance thereof for the modern corporate environment and the management of the corporate treasury department.

\section{Research methodology}

The information was gathered by way of:

- a survey of available literature on information systems and e-businesses in the treasury environment;

- informal discussions with important role players at the annual conference of the Association of Corporate Treasurers of Southern Africa and other conferences and seminars to establish their points of view on current and future changes in the role and position of the corporate treasury department; and

- informal discussions with corporate treasurers to establish their points of view on current and future changes in the role and position of the corporate treasury. 


\section{Overview of the most important developments in information technology and business environment during recent years}

To determine how the corporate treasury will develop in the future, it is necessary to view the traditional role of the treasury department and developments in the business environment over recent years.

In earlier years, information systems were used because it was fashionable. Companies spent vast amounts on information technology (IT) in an attempt to automate various processes without duly considering the cost-benefit implications. Systems were immature and in many instances did not satisfy the needs of users.

As the years passed, that emphasis shifted to one where investment in information technology could only be justified if it could be used to add value to the activities of the enterprise. This is confirmed by St Clair (2000:54). According to Laudon and Laudon (1997:45), the value chain model seeks to highlight specific activities in the business where competitive strategies can be best applied. The value chain model is therefore used to identify those leverage points where information systems can be used by the enterprise to enhance its competitive position.

Over recent years the treasury department was also affected and therefore had to change due to the need for:

- corporate downsizing and the need for an ever-leaner cost basis;shared service centres;

- better manage risk and to reduce errors and timely delays; and

- integrated systems.

One of the major problems that corporate enterprises used to face and is still facing today has to do with the fragmented nature of systems. Deficient integration of different systems into one system that is capable of a seamless movement of inputs and outputs hampers the operations and management of the business in many respects. However, the situation has improved over recent years.

Generally, the business environment is undergoing major changes. This is driven to a large extent by the Internet and the Web. This technology creates many new possibilities or dimensions for payments and receipts, creation and access to information, relationships with clients and, generally, for planning purposes. The Web also assists in the integration of systems across the supply chain (Hardy 2002:90).

Pederson (2000) describes changes brought about by the Web as follows:

- New channels are revolutionizing sales and brand management

- The balance of power is shifting to the customer

- Competition is intensifying across all dimensions

- The pace of business is fundamentally accelerating

- Companies are transforming into extended enterprises

- Companies are re-evaluating how they, their partners and their competitors add value.

These changes imply major changes for the enterprise over the long term. From the above it can be deduced that the changes especially impact on the strategic position of the enterprise.

The changes affecting the enterprise as a whole will also have a major impact on the treasury department in a company. Whether the treasury department personnel consists of one or several employees, e-business will have a major impact on the way the department is 
managed and its position within in the enterprise.

\section{Role and function of the corporate treasury department}

Within the enterprise, the treasury manager has always been seen as the officer responsible for the receiving, safe keeping and disbursement of negotiable value.

The specific functions of the corporate treasurer may be broken down into the following (Money management manual, 2001: V.1.9, adjusted):

- Liquidity and cash management, which has to do with the short-term management of cash and liquidity. This is the primary function of the treasurer.

- Currency management, which involves the converting and hedging of currency receivables and payables and the management of the impact of currency movements on balance sheet gearing and net worth.

- Funding management, which involves arranging bank and capital market debt. The board of the enterprise decides on the level of debt and the treasury manager will decide on how best to resource it in terms of instrument, maturity, currency, interest basis, documentation and day-to-day management of the relationship with the provider.

- Corporate finance, which is the managing of financial structure (e.g. ratio of debt to equity) to minimize the cost of capital to the company.

- Risk management, which may focus on the management of the exposure to pure risk as well as financial risk. It stands to reason that since the treasury department is responsible for risk management, managing other risks may also be its responsibility.

Although these functions are fundamentally still the same today, important changes in the financial and business environment, as mentioned above, took place over recent years, underlining the need for change. The treasury department is the department from where these functions are executed. Treasury management therefore refers to the actions by an organization or department that are necessary to plan, implement, monitor and control the various treasury functions as listed above.

Treasury management and the expertise it can offer will become more important in due course owing to:

- the conducting of business in a more complex financial environment, requiring the expertise that treasury staff can offer;

- increased volatility present in financial markets, which requires better and more risk management;

- globalization that opens new doors but creates more complexity;

- the conducting of e-business or business in cyberspace, bringing many new benefits; and

- new (e-)exposures, financially and otherwise.

In addition to the above factors, companies today can suffer enormous losses directly owing to the actions of a single individual, but which may have been prevented by the appropriate supervision (Holton 1998). There are many sources of leverage today that expose companies to more risk, namely derivatives, repos, securities lending and structured notes (Holton 1998). These financial tools can cause significant damage in the wrong hands.

The Internet is linking many systems and participants in the market place, creating new 
mechanisms for movement of funds and thereby creating new benefits but also new problems or risks.

Various benefits may be realized due to e-business or the Web or Internet environment. According to the literature survey, the integration and development of systems in a Webbased environment may lead to the following important benefits:

- The setting up of various new Web-based e-finance services means that clients can be Web-enabled for self-service (Thurston 2000).

- Web-based e-services lead to a reduction in overheads or increased productivity as resources can be reallocated to critical areas.

- E-business gives rise to much more data (even for the medium-sized business) that can form the basis of decision information through statistical analysis (Wood 2000:13).

- Web-based treasury management and financial services will lead to a broader and more global client base for e-finance service providers (Thurston 2000).

- There is better integration of cash flow into back-office operations (Thurston 2000).

- Better access to information is possible via the Internet from any location, which improves and shortens the management cycle and efficiency. Treasury managers also need various types of information, including economic forecasts, sales and purchase forecasts and information on cash flow, data on corporate planning and market rates, for many types of financial transactions (Forster 2000). These are all supported in an unprecedented way by the Internet.

- Electronic bill presentment and payment open new marketing and communication channels with clients (Marjanovic 1999).

- Browsers are used universally, and development in this area tends to be cheaper than development with dedicated treasury management software (Jones 1999).

- Many Web-based development tools make use of object-orientated programming techniques that facilitate updating and maintenance of code.

- Owing to the lower cost of development and the use of browser-based technology, small companies can also participate in electronic data interchange (Jones 1999).

- Owing to the fact that Web-based software resides in one location, less maintenance is required to update or change software (Markovic 1998).

Integration of systems and development in a Web-based environment lead to the following disadvantages:

- Setting up various links and expanding business through e-business lead to new problems such as greater exposure to financial risk. This emphasizes the need for better risk management (Thurston 2000) which may, on the other hand, improve with better integration of treasury systems as risk can then be better managed at corporate level.

- Security becomes an issue as integrated systems give access to much more data, increasing the risk.

- Lack of security tends to prevent some companies from moving their financial activities to the Internet (Wood 1999:26).

- The speed and reliability of Web-based delivery channels are suspect. The treasurer is dependent on the service of the Internet service (ISP) provider when not using its own server.

According to St Clair (1998:54), some areas of treasury management are outsourced due to low growth and low cost. As a result, some of the activities the treasury manager traditionally did are diminishing. Treasury managers therefore have to reapply their skills to a wider array of functions or face the risk of becoming redundant. This situation is exacerbated by e-business and Web-enabled systems that also free resources. Figure 1 
illustrates how the work of the treasury manager or expert is becoming more diverse. The shaded area indicates the traditional activities whereas the light areas indicate the added activities.

\section{Figure 1 Model for treasury activities (St Clair 1998:54)}

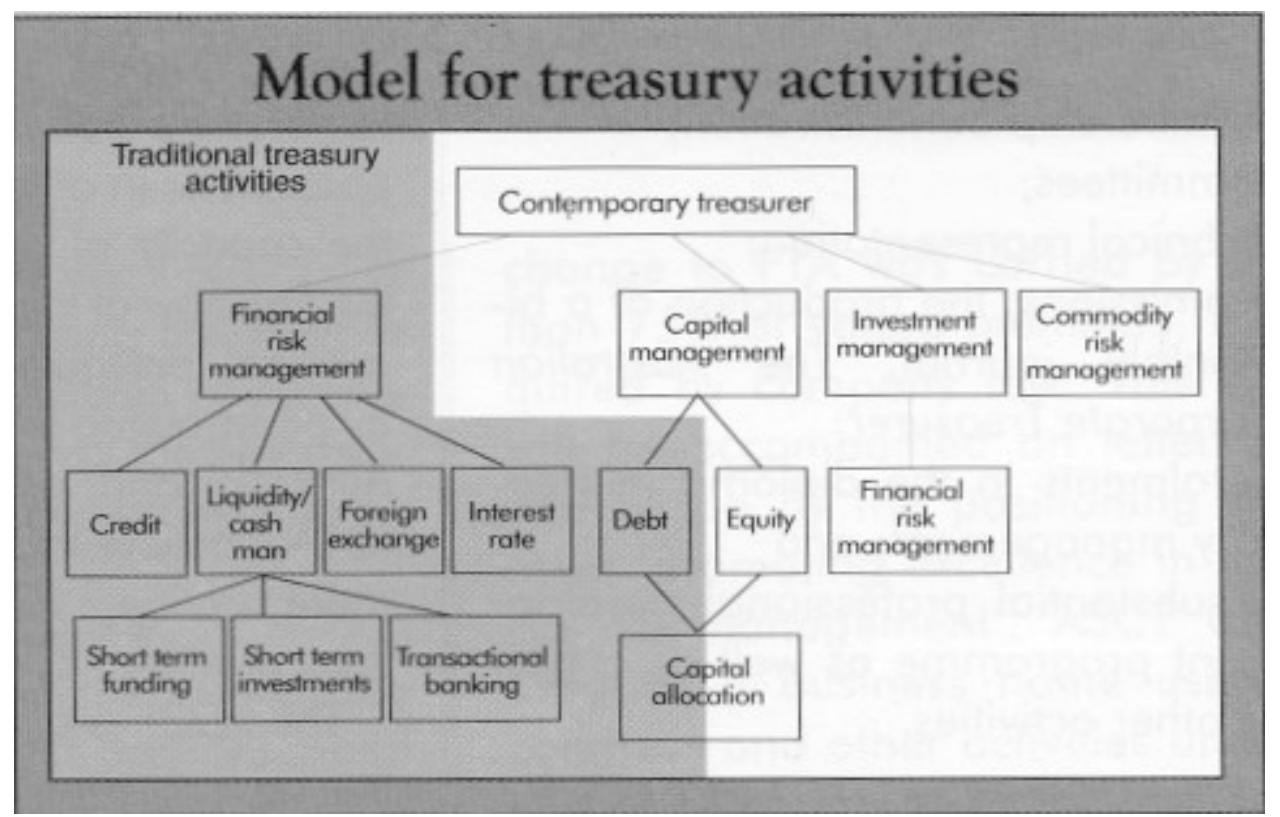

To survive in the new economy, there has to be convergence of technology (Emmett 2002:19). Sound conventional business sense and an attempt to understand and assist customers should prevail (Emmett 2002:19). Businesses have to make use of technology - in this case the Internet - to add functionality or to improve or extend existing business processes.

The extension of the business processes refers to added services that can be offered to clients through the Internet. For instance, screens and access that enable clients to structure settlements with the company in such a way that the client can make most use of available credit, lower exposure to the company and optimise liquidity with the company will become possible.

Although it is often said that businesses will not survive if they do not have a presence on the Internet, it must be understood that if the treasury does not develop a Web presence, the business will still go on as before. However, over time, the corporate treasury will not be able to realize many of the benefits that technology has to offer; the effectiveness of treasury will decrease and will eventually be forced to utilize the Internet as it will not be able to strategically position itself and benefit the enterprise as a whole. It must also be emphasized that the corporate treasury will not be equally important in all companies, but should become more important in most companies.

According to Holton (1998), there are three fundamental elements that should comprise any risk management strategy:

- Corporate culture

- Procedures

- Technology.

It is logical that technology should feature in this list as it certainly has become an important strategic tool that the corporate treasurer cannot ignore. 


\section{New emerging role and position of the corporate treasury department}

Technology should play an important role in the future of the business and more specifically the treasury department. For the treasury department to cope with the new demands that may emerge in the modern business environment, corporate treasuries should plan for the future and be well aware of future possibilities. Some changes should be planned today to realize the benefits tomorrow. The e-business environment and general changes in the financial environment imply a new dimension in treasury management. There is a need to work more closely and collaboratively with strategic business partners, which in turn raises new challenges of trust, security and openness (Pederson 2000).

In view of the issues highlighted in the previous sections, the following important points should be highlighted:

\subsection{Data warehousing}

Meaningful analysis and management of a business rest primarily on having meaningful information about all aspects of the business activities. More often than not, businesses do not have sufficient information for management purposes. As mentioned before, one of the major problems that most businesses face is the fact that information systems are often fragmented or incompatible. In addition, systems often do not contain all the information needed to support managerial decision-making. Where systems cannot supply the information manual analysis is often done in spreadsheet format to produce management information. This certainly is not efficient and too dependent upon the human element.

What is needed to support all aspects of risk and treasury management and general management of the business is data warehousing. This concept refers to the construction of containers of information gathered from all over the enterprise, available for a wide variety of uses on group or individual level (Robson 1997:418). The centralized data warehouse should contain all the information needed for management purposes - this implies that in the first place systems should be capable of supplying the information. If this is not possible, systems will have to be redesigned or re-engineered to supply in the data warehousing and eventual management needs.

The construction of a data or information warehouse is a mammoth task in terms of complexity and difficulty, and must not be underestimated by the company. Corporate treasuries should start planning and developing to make sure that the business demands will be satisfied in the future. Here the cost of development, the cost of acquiring software from other countries and in-house development should be properly considered.

Apart from the data warehouse, on-line analytical processing (OLAP) support is needed to retrieve meaningful information for management purposes from the data warehouse (Robson 1997:418). Once again, the corporate treasury should plan for this process. In this regard, ebusiness systems can facilitate gathering and integrating the needed information for the data warehouse.

\subsection{Traditional treasury role}

Liquidity management and cash management will still be the basic responsibilities of the corporate treasurer. However, certain other functions will start playing a much more important role in the future. Funding management, corporate finance and risk management will become more prominent. Support functions in other departments that affect the risk and general effectiveness of use of available resources will become vital. One example here would be where treasury staff helps improve the cash conversion cycle to free funds which 
can be pushed into growth opportunities and other financial investments, thereby improving the bottom line.

\subsection{Complex financial management services}

According to Pederson (2000), '[if] managing risks systematically, proactively and consistently, an organisation can take more risk than its competitors, [and] the rewards will be commensurate'.

Owing to the influence of a changing business environment brought about by e-business and market changes in terms of volatility and risk, the treasury function will become much more focused on the enterprise as a whole. Recent corporate management problems in the USA underline the need for a more holistic approach rather than concentrating mostly on the management of cash and the management of financial risk at departmental level. If risk is managed effectively at corporate level, the enterprise can possibly take on more risk, which may result in more profit.

However, the treasury will be able to extend its services and will be required to do so due to the changing business environment.

\subsection{System enterprise-wide risk management}

It is often said that risk is best managed at the highest level in the enterprise, that is, at the corporate level. It means that risk management should therefore take the whole organization into account and evaluate the interaction of the various types of financial risk in the enterprise. All risks to which the enterprise is exposed should be considered when managing risk. The risk exposure of the subparts of the enterprise is not similar to the risks that the total enterprise is exposed to. As was mentioned before, sources of risk are different today and much more of the capital of an enterprise can easily be placed at risk with single transactions.

Owing to the volatility and risk inherent in the business environment and the additional power that technology brings, system enterprise wide risk management (SEWRM) is becoming increasingly important. The addition of 'system' here attempts to highlight the fact that the function should be based on a (computer) system. In this context, the importance of the data warehouse is underlined in that it will help avoid double counting or duplication of financial risks, and interrelationships will be more clearly observed.

As mentioned before, the SEWRM should be supported by a proper centralized data warehouse (Dowd 1998).

\subsection{Risk management process}

The financial risk management process, as shown in Figure 2, will be reinforced by anticipated changes due to e-business. The process of starting with the identification of risks, evaluating or measuring, determining the appropriate strategy to counter risk, implementation of the chosen strategy and periodic re-evaluation will become more important.

\section{Figure 2 Financial risk management process}




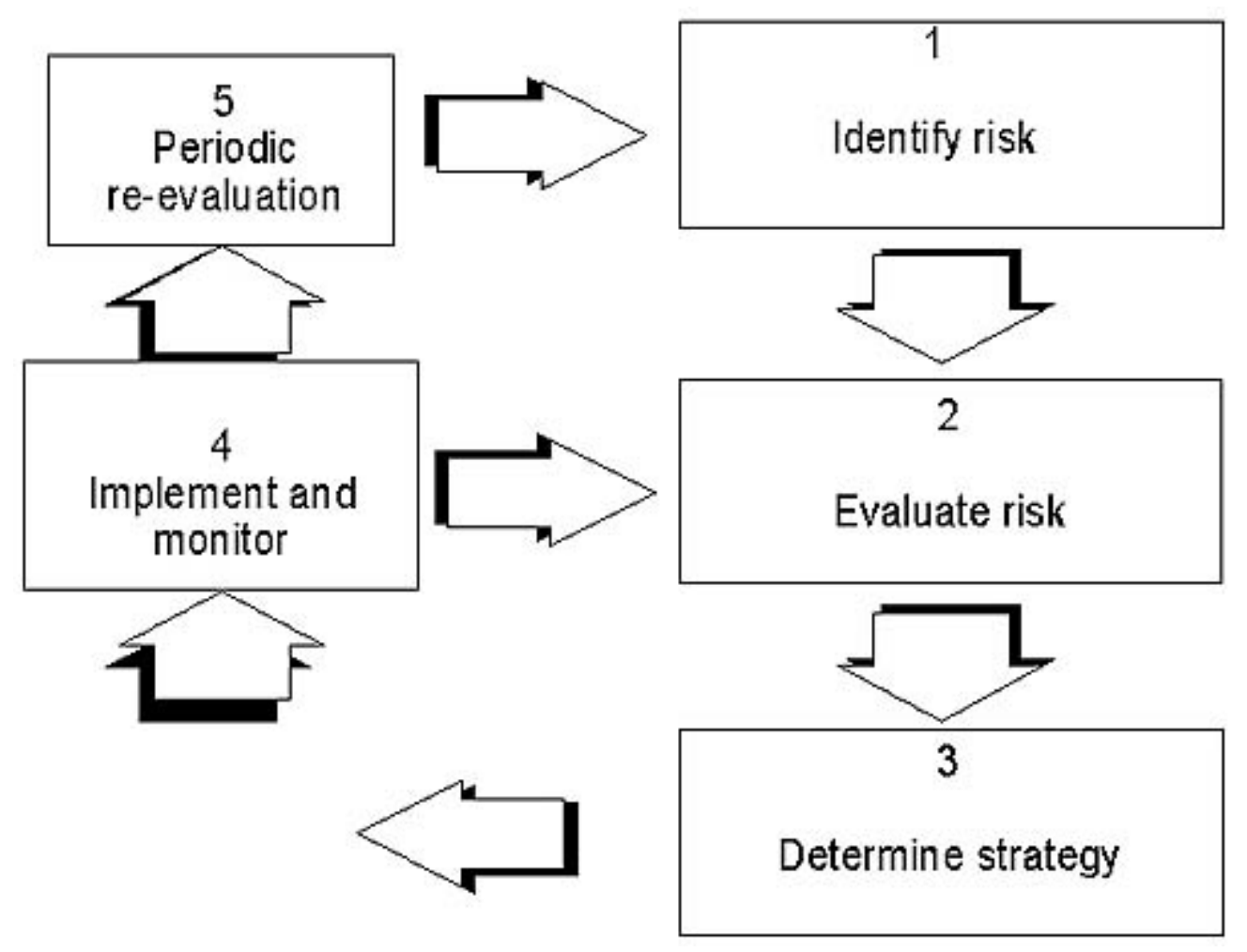

top

\section{Importance of the future treasury from a management point of view}

The change in the importance of treasury from a management point of view may briefly be summarised under points 7.1 to 7.5 below.

\subsection{Strategic importance of treasury}

The strategic importance of treasury will undergo change. The following are some of the most important changes:

- A far more important strategic position for treasury will become evident

- A deeper business knowledge will be required from treasury specialists

- Within the enterprise, the treasury will add value in the business sense

- SEWRM will be a vital element of the proper management of the enterprise

\subsection{Better planning and allocation of resources}

E-business and better systems will give rise to more information being available for management purposes. More and better information will be available for business planning.Resources will be freed (due to more automated and integrated systems). This will lead to increased returns on assets employed.

\subsection{Management control}

Also, this aspect of management will change. The following are some of the most important aspects that may be mentioned:

- Treasury will add value through SEWRM

- Remote control and management of portfolio, clients and systems via the Web shorten the management cycle and time to react to changing market conditions

- More unified and visually effective way of looking at information making interpretation less time consuming 
- Many levels of customisable security from any location, also unified, enhancing complete control over valuable information from any location for clients and internal users

- More complete information for risk management and planning purposes more readily available - emphasis on the enterprise (group) as opposed to departments

- Information more accurate and more automated

- Less human intervention and increased productivity

- Possible greater emphasis on adding value via risk management and on business processes as opposed to internal intricacies

\subsection{Extension of the treasury function}

The treasury function will expand owing to the change in the way resources are used and owing to market changes driven by e-business. Some of the most important drivers of the extended treasury function are:

- Greater emphasis on external relationships and links to other Web sites and clients and companies

- More services will be offered through e-business facilities to clients

- 'Self-help' corporate finance can become more viable

- A degree of 'self-help' risk management services

- Improved self-help cash management services

- All extended facilities also available to departments in the enterprise

\subsection{More advanced systems and less human intervention}

Owing to the further development of computer systems and the ease with we do business, and owing to improved/intelligent systems, some routine aspects of the treasurer's work will undergo change. In this regard, the following may be mentioned:

- Straight through processing (STP) will be implemented.

- Less human intervention - systems will make automatic adjustments to the risk exposure and movement of information and documentation will be automated in the ebusiness environment

- Remote control of the treasury will be possible through the Internet, which may also allow more transparency from the point of view of the investor.

For South Africa, the above points are especially relevant. Although the direction of a company is dependent on what the board approves in terms of policies and risk appetites, it is also influenced by what happens in the business environment. Every company is different but similar external forces often influence all of them. In this sense, the corporate treasury will also be influenced by market changes. To adhere to good practice in treasury management, a company will often have to change to bring its practice in line with other treasuries.

There should be no doubt that the treasury department is a value-adding department. Some corporate treasurers still today, especially in South Africa, refuse to accept this fact. The reasons why the treasury should be seen as a value-adding department are as follows:

- Technology (e-business and the World-Wide Web) makes it more possible to manage overall company financial risk - a job best done by the treasury expert.

- The Web will become much more advanced and flexible than it is today (Gillmore 2002:59). Much more will be possible in terms of risk management and the exploitation of new business opportunities; more actual applications will run on the Internet, increasing its usefulness and value for the modern enterprise. Treasury, which will be lifted to a higher level in the enterprise, will therefore become an important 
business division of the modern enterprise and should therefore also add value like any other department. The Internet improves the internal efficiency (such as increasing productivity, saving time) of the treasury and the enterprise as a whole. The treasury can contribute substantially to the bottom line of the enterprise.

- Owing to the fact that e-business is freeing resources in the treasury department, it makes sense if treasury expertise is used where it can make a difference to the overall business and therefore add value in various departments.

Figure 3 elucidates the future treasury model that should emerge in South Africa in the next number of years. Central to everything that the enterprise does is the data and information warehouse. Information created through transactions with clients through the Internet and with other departments in the enterprise through the intranet is fed through to the operational systems, which again feed into the data warehouse, pooling all important information. Information is created primarily for use at three levels, namely, at transaction, management and corporate level.

In addition to the data warehouse, the treasury extracts information through on-line analytical processing from which risk management decisions are made. As a result, action will be taken to adjust the overall risk positions with derivatives and/or other services in the company which are aimed at improving the utilization of resources or lowering of financial risk.

It may be argued that treasury should make certain information available to investors regarding the overall risk policies and risk position of the enterprise via the Internet to create a degree of transparency and avoid some of the corporate governance problems as experienced in the USA in recent times. However, research about this issue fell outside of the scope of this research.

\section{Figure 3 Future treasury management model}

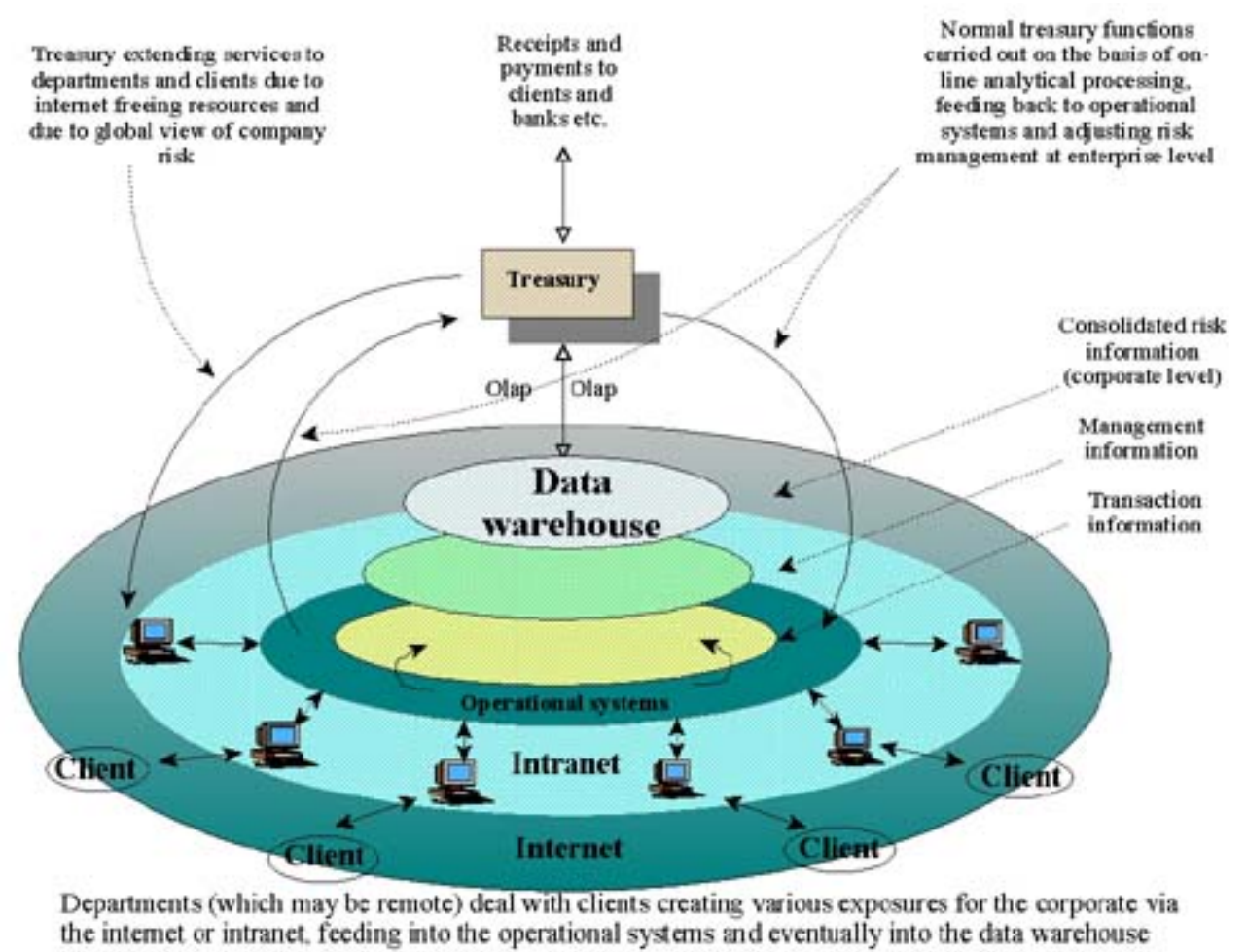

The above discussion highlights one very important aspect that will materially affect the future position of treasury departments: The management of the corporate treasury must ensure the total integration of the overall long-term business strategy, the treasury strategy 
and the information technology strategy so that:

- maximum exploitation of the business opportunities are supported by the benefits of IT;

- maximum use and protection of valuable information are made possible through the use of IT;

- optimal use is made of IT to ensure exploitation of the above objectives and maximum exploitation of business opportunities in all circumstances;

- optimal use of available funds is ensured through the use of better, more advanced and more accurate systems;

- optimal management of financial risk at corporate level is supported by complete information and systems that use information to its fullest; and

- maximum use is made of treasury expertise to service clients and the company itself.

\section{Summary, conclusion and recommendations}

In this article, some important factors that influence the treasury department today and in the future are discussed. Material change will be driven by the e-business environment and the need for better risk management at corporate level. Recent turmoil in the American corporate world has highlighted the need for more transparency and better management at the highest level. In this regard the treasury department of the future will be well placed to add substantial value and help the enterprise make better use of available resources.

Deriving maximum value from the market place requires a solid business plan and an understanding of where the company strategically wants to be in the future. As important as it is to take note of the business tendencies, it is to take into account the infrastructures that will enable an enterprise to better exploit business opportunities. When an enterprise does business it creates financial risk. The risk exposure can be very material in relation to the financial resources of a company and therefore has to be managed sensibly. The reward is not only the continued existence of the company, but also that the available financial resources are better employed to add more value to the bottom line of the company.

To get the correct treasury focus in the enterprise for the future, the enterprise should ensure that the overall business strategic plan, treasury strategic plan and IT strategic plan are integrated. Put differently, the treasury and IT strategic plans should find their rightful place in the overall business strategic plan of the enterprise.

The treasury model described in this article underlines the future of treasury department. Those who take note of this today will be the winners of tomorrow. Building a data warehouse and positioning treasury over this valuable resource will be the winning combination.

Companies should possibly make their risk management policies and procedures transparent and publish them on the Internet to enable investors to judge for themselves the relative value of risk and treasury management for the continued existence of the enterprise.

Corporate treasurers must take note of global developments and tendencies towards building a presence on the Web. Planning for this today is important, as it will ensure that the corporate treasury will develop into a sophisticated operation that adds substantial value. Early planning will also ensure that an enterprise will be able to benefit from vast Web developments expected in the future that may allow many new business opportunities and much more flexibility. 


\section{References}

Duffield D. 2001. Understanding e-business risk management: Getting it right leads to success. Cover 14(4):18.

Emmett, M. 2002. Getting the best of both worlds. Financial Mail (19 April):12.

Forster, W. 2000. Treasury management and the use of the Internet. [Online]. Available WWW: http://www.gtnews.com/articles3/2023.html (Accessed 20 March 2002).

Gillmor, D. 2002. Mister Web looks ahead. Financial Mail (24 May):15.

Gordon, G. 2000. E-enable now, or else. Professional Management Review (November):1011

Hardy, A. 2002. Are you Web ready? Financial Mail (19 April):43.

Holton, G.A. 1998. Enterprise risk management. [Online]. Available WWW: http://www.contingencyanalysis.com/erm1.htm (Accessed 8 April 2002).

Jones, R. 1999. Treasury management systems moves onto the Internet in 1998. Web Finance 1(3):7. [Online]. Available WWW: EBSCOHost/Business Source Premier/1559799 (Accessed 9 February 2001).

Laudon, K.C. and Laudon, J.P. 1998. Information systems and the Internet, 4th ed. Dryden: Fort Worth.

Marjanovic, S. 1999. Checkfree chief to bankers: go with the Internet flow. American Banker 164(29):12. [Online]. Available WWW: EBSCOHost/Business Source Premier/1553382 (Accessed 9 February 2001).

Markovic, P.J. 1998. Internet technology: key issues for the treasury managers. TMA Journal 18(6):30. [Online]. Available WWW: EBSCOHost/Business Source Premier/1513428. (Accessed 9 February 2002).

Older, wizer, Webbier. 2001. The Economist (30 June):10.

Pederson, L. 2000. E-risk management: global treasury news. [Online]. Available WWW: http://www.gtnews.com/articles4/2262.shtml (Accessed 20 March 2002).

Robson, W. 1997. Strategic management and information systems: an integrated approach, 2nd ed. London: Pitman.

St Clair, I. 1998. The contemporary treasurer. The Treasurer (September):54.

The Associate Membership Programme in Treasury Management. 2001. Money Management manual: Reproduced with permission from the Association of Corporate Treasurers (UK) for the Centre for Business Management, UNISA, Pretoria.

Thurston, C.W. 2000. Integrating treasury management. Global Finance 14(7):49. [Online]. Available WWW: EBSCOHost/Business Source Premier/3350866. (Accessed 9 February 
2001).

Wood, K. 1999. Internet security solutions - seven ideas. TMA Journal 19(1):26-29.

Wood R. 2000. E-business will take over the future. Professional Management Review: (November):13.

\section{Disclaimer}

Articles published in SAJIM are the opinions of the authors and do not necessarily reflect the opinion of the Editor, Board, Publisher, Webmaster or the Rand Afrikaans University. The user hereby waives any claim he/she/they may have or acquire against the publisher, its suppliers, licensees and sub licensees and indemnifies all said persons from any claims, lawsuits, proceedings, costs, special, incidental, consequential or indirect damages, including damages for loss of profits, loss of business or downtime arising out of or relating to the user's use of the Website. 